\title{
Self-management and Medication Adherence in Older Adults with Type II Diabetes Referring to the Endocrinology Clinics of the Teaching Hospital Affiliated to Iran University of Medical Sciences (2019)
}

\author{
Fatemeh Epakchipoor ${ }^{1}$, Farideh Bastani ${ }^{2}$, Fatemeh Pashaei Sabet ${ }^{3}$
}

\begin{abstract}
Background \& Aims: The world's population is ageing, and the elderly constitute large number of the world's population. With ageing, the health status undergoes certain changes, and the risk of developing chronic diseases and disabilities increases in the final years of life. Given the increased index of life expectancy and the subsequent increase in the number of the elderlies in the world, the number of diabetic patients in this population also increases. Diabetes is an important health issue and a common physical illness, which causes numerous complications in old age. Type II diabetes has no definite diagnosis and requires long-term care and proper selfmanagement. Since diabetes has no definite treatment, the early identification of the suspected cases could prevent and delay the associated complications through proper self-management. The self-management of diabetes is complex and may go beyond blood sugar control, requiring the balancing of multiple metabolic and lifestyle factors and helping the patients to discover and exploit their capabilities in this regard. If patients with chronic diseases refrain from self-management and do not actively partake in self-care, positive clinical outcomes will be hard or impossible to achieve. Self-management is a rehabilitative method in which the care activities mainly depend on the patient, and the aim is to attain maximum independence, decision-making, and health improvement based on the abilities and lifestyle of the patient. Therefore, self-management must be evaluated in vulnerable and targeted populations, such as the elderly. Due to the chronic nature of diabetes, the patient must follow a special, long-term medication regimen that is prescribed by the treatment team, which is only possible with the active participation of the patient in the treatment and implementation of the recommendations of the treatment team members; this is referred to as treatment adherence. One of the main concerns and clinical problems that is frequently faced by healthcare providers is the problems associated with the lack of adherence to the prescribed treatment, particularly in the patients with chronic diseases that require long-term treatment. In the absence of proper self-management and medication adherence in elderly patients, heavy costs of the treatment of the disease and its complications will be imposed on the patients, their family, the community, and the health system. In addition, the subsequent psychological and social costs should be considered in this regard, and special attention has to be paid to this issue. Several studies have shown the unsatisfactory state of self-management and medication adherence in elderly diabetic patients, emphasizing on the periodical and frequent assessment of this issue. Given the necessity of healthy, active, and successful aging, the present study aimed to evaluate self-management in the elderly with type II diabetes in the teaching hospitals affiliated to Iran University of Medical Sciences.

Materials \& Methods: This descriptive, cross-sectional study was conducted on the elderly patients with type II diabetes referring to the endocrine clinics of the teaching hospitals affiliated to Iran University of Medical Sciences. The patients were selected via continuous sampling during January-May 2020. For the evaluation of self-management and treatment adherence in the patients, the minimum sample size was estimated at 280 patients at the confidence level of $95 \%$, accuracy of $d=0.2$, and standard deviation of 1.7 . The inclusion criteria of the study were age of more than 60 years and less than 75 years, at least one year since the definitive diagnosis of

1. Ms in Geriatric Nursing, Department of Community Health Nursing and Geriatric Nursing, School of Nursing and Midwifery, Iran University of Medical Sciences, Tehran, Iran

2 . Department of Community Health Nursing and Geriatric Nursing, School of Nursing and Midwifery, Iran University of Medical Sciences, Tehran, Iran. (Corresponding Author) Tel: $+982143651820 \quad$ E mail: bastani.f@iums.ac.ir 3. Department of Community Health Nursing, School of Nursing and Midwifery, Iran University of Medical Sciences, Tehran, Iran.
\end{abstract}


diabetes by a physician, treatment with antihypertensive drugs for a minimum of six months, and no cognitive impairment with the score of $\geq 7$ in the abbreviated mental test (AMT). Data were collected using the short-form AMT, a demographic form, diabetes self-management questionnaire (DSMQ), and drug adherence questionnaire (MMAS). After the completion of the questionnaires by the researcher, the data were coded, and the analysis of the raw data was performed using descriptive statistics (adjusting frequency distribution tables, calculating frequency indices, and frequency numerical indices) for the qualitative variables. In addition, the minimum, maximum, mean, and standard deviation were determined using inferential statistics and Chi-square, independent t-test, analysis of variance (ANOVA), Pearson' correlation-coefficient, Scheffe post-hoc test, and regression analysis at the significance level of $\mathrm{P} \leq 0.05$.

Results: The mean age of the patients was 66.64 years, and the majority were married (6\%). Based on the questionnaire data, $77.1 \%$ of the elderly patients had at least one underlying diseases, and patients with cardiac diseases constituted the majority in this regard (50.4\%). In addition, the duration of the disease was more than five years in most of the patients $(70.4 \%)$ (Table 1$)$. On a scale of $0-10$, the mean score of self-management in the elderlies was 6.55 , and $63.2 \%$ of the research units obtained a higher score than eight in drug adherence, which indicated favorable self-management and drug adherence. According to the data obtained by the multivariate analysis and among the regression factors, the variables of education level $(\mathrm{P}=0.017)$, housing status $(\mathrm{P}<0.001)$, and income adequacy $(\mathrm{P}=0.01)$ were significantly correlated with self-management. Furthermore, selfmanagement in the domain of physical activity (mean score: 7.07) had the highest mean score, while the domain of diet control (mean score: 6.05 ) had the lowest mean score compared to the other domains. Self-management had a significant correlation with education level $(\mathrm{P}=0.017)$ and income adequacy $(\mathrm{P}=0.01)$. The results of independent $\mathrm{t}$-test also showed that self-management was significantly lower in the unmarried patients (single/widowed/divorced) compared to the married elderlies $(\mathrm{P}=0.003)$. Drug adherence was significantly lower in men compared to women $(\mathrm{P}=0.015)$ and had significant correlations with education level $(\mathrm{P}=0.001)$, employment status $(\mathrm{P}=0.013)$, and income adequacy $(\mathrm{P}=0.019)$.

Conclusion: According to the results, self-management and drug adherence were generally satisfactory in the elderly patients with type II diabetes. However, self-management was significantly lower in the patients who were illiterate, unmarried (single/widowed/divorced), and had an insufficient income, regarded as the vulnerable segment of the society. Therefore, this group of elderlies needs more attention from the health system and healthcare planners, as well as educational-counseling interventions based on the empowerment of vulnerable elderlies in order to promote self-management behaviors, minimize the complications of diabetes, and experience a healthy, active, and successful aging.

Keywords: Type II Diabetes, Self-management, Medication Adherence, Elderly

\section{Conflict of Interest: No}

How to Cite: Epakchipoor F, Bastani F, Pashaei Sabet F. Self-management and Medication Adherence in Older Adults with Type II Diabetes Referring to the Endocrinology Clinics of the Teaching Hospital Affiliated to Iran University of Medical Sciences (2019). Iran Journal of Nursing. 2021; 34(129): 1-14.

Received: 2 Jan 2021

Accepted: 3 Apr 2021 


\title{
خود مديريتى و تبعيت دارويى در سالمندان مبتلا به ديابت نوع دو در مر اكز منتخب آموزشى درمانى دانشكاه علوم يزشكى ايران
}

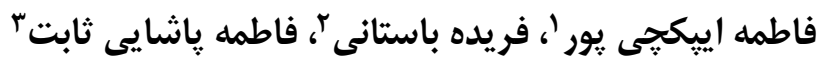

جكيله

زمينه و هدف: بيمارى ديابت نوع دو با خود مديريتى و تبعيت دارويى جالش برانكيز مواجه است. لذا هدف اين مطالعه تعيين خود مديريتى و تبعيت دارويى در سالمندان مبتلا به ديابت نوع دو در مر اكز آموزشى درمانى دانشكاه علوم بزشكى ايران بود تا بتوان بر اين مبنا برنامهريزى مناسبى در جمعيت آسيب بذير سالمندان انجام داد.

روش بررسى: اين يزوهش يكى مطالعه مقطعى (توصيفى) بود. جامعهى يزٔوهش سالمندان مبتلا به ديابت نوع دو مراجعه كننده به مراكز آموزشى-

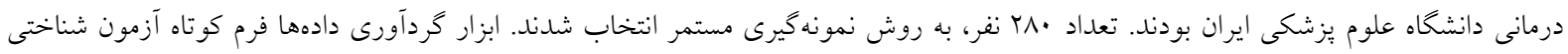

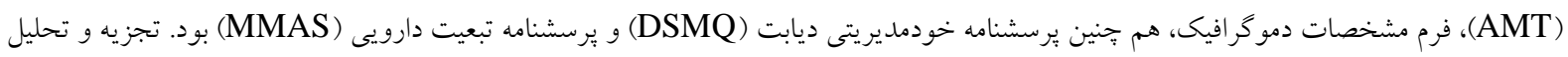

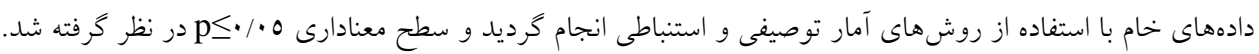

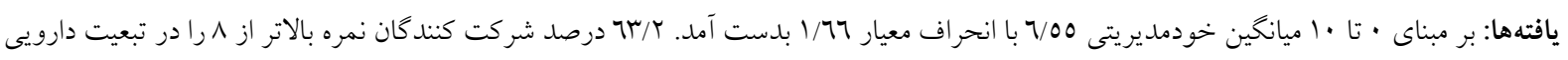
بدست آوردند كه نشان دهنده خودمديريتى و تبعيت دارويى مطلوب بودهائ است. خود مديريتى با متغيرهاى تحصيلات، مسكن، و كفايت درآمد ارتباط

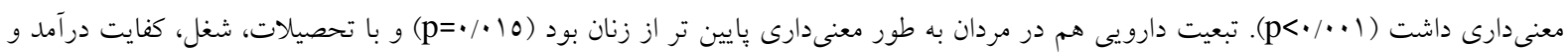

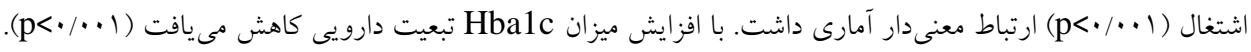

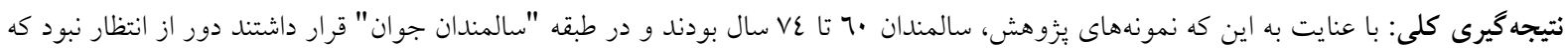

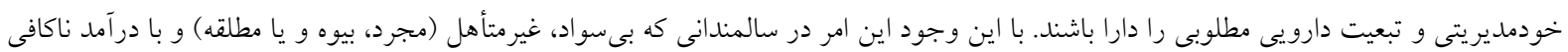

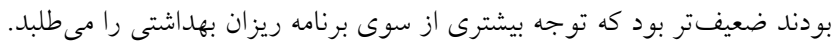

كليد وازهها: ديابت نوع دو، خود مديريتى، تبعيت دارويى و سالمند

تعارض منافع: وجود ندارد.

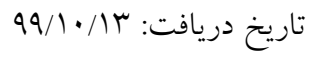

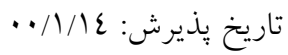

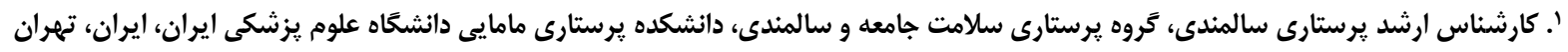

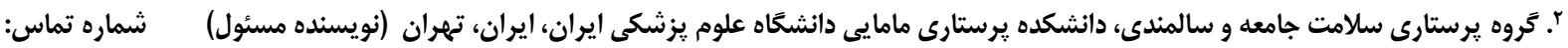
Email: Bastani.f@iums.ac.ir ET701AT. "ا تَروه يرستارى سلامت جامعه و سالمندى، دانشكده يرستارى مامايى دانشكَاه علوم يزشكى ايران، ايران، تهران 
ميانخين اين هزينه براى يك فرد مبتلا به ديابت در ايران

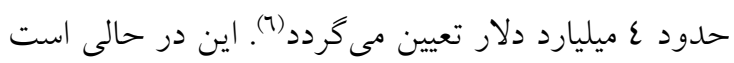

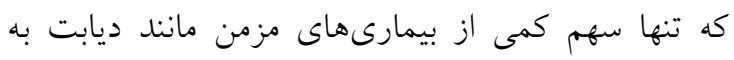

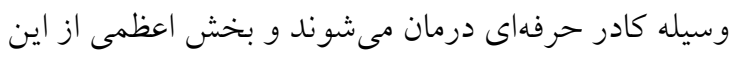
بيمارىها توسط خود فرد و خانوادهاش مديريت و كنترل مىشود. خودمديريتى ديابت يك مؤلفه اساسى در مبتلايان به ديابت نوع دو است و از دهه ·س ·19 به عنوان بخش مهمى از مديريت بالينى بيمارى مورد توجه قرارگرفته است كه نيازمند ايجاد تعادل بين بسيارى از عوامل متابوليك و

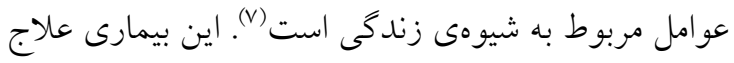
قطعى ندارد و با شناسايى به موقع و مراقبت صحيح بر يايه

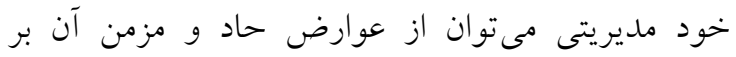
اركانهايى همجيون قلب و كليه ها بيشخيرى كرد يا بروز آن

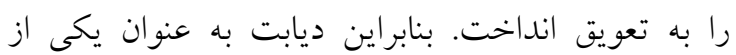

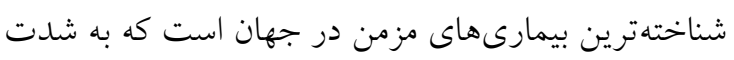
باعث افت سلامتى افراد مبتلا، خصوصاً در سالمندان

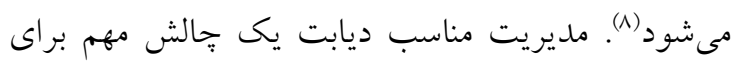

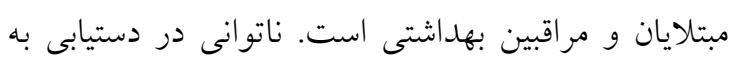

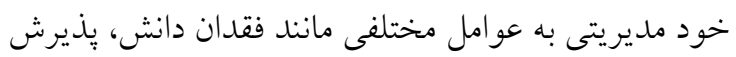

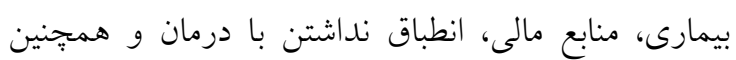

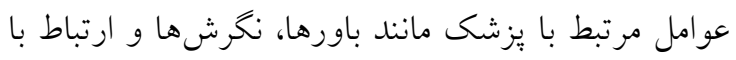

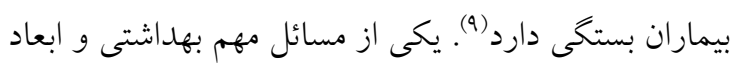

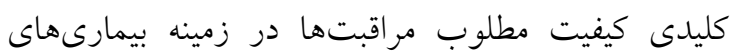
مزمن موضوع تبعيت دارويى است. با توجه به ماهيت مزمن

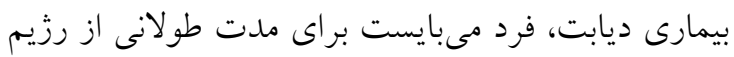
دارويى خاصى كه توسط تيم درمانى ارائه مى نود، تبعيت نمايد و اين امر تنها با مشاركت فعال بيمار در امور درمان و اجراى توصيههاى اعضاء تيم درمان ميسر است كه از آن تحت عنوان تبعيت از درمان ياد شده است. تبعيت نكردن بيماران از رزيمهاى دارويى و غذايى و يروتكل هاى درمانى و بهداشتى با عواقب اقتصادى و درمانى قابل ملاحظهاى همراه است، براى مثال بيماران با تبعيت نكردن دارويى در

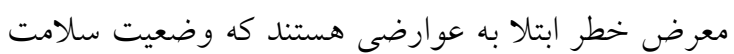

\section{مقدمه}

جمعيت جهان به سرعت در حال بير شدن است و سالمندان درصد زيادى ازجمعيت دنيا را تشكيل مى دهند. در حال حاضر سالمندان Y| درصد جمعيت دنيا را تشكيل مىدهند. بر اساس آخرين گزارش اعلام شده از طرف سازمان جهانى بهاشت در سال •0.0. جمعيت سالمندان

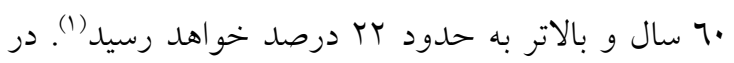
ايران نيز بر اساس سرشمارى عمومى نفوس و مسكن مركز

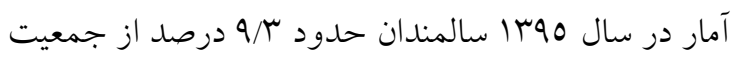
كشور را تشكيل مىدهند. ديابت يكى از مشكلات سلامت عمومى در سالمندان است و يكى از علل مهم ناتوانى و مرگ در سراسر جهان است و ميليونها نفر را مبتلا مى كند. اين بيمارى معمولاً با ساير شرايط بزشكى همبستخى دارد و شيوع آن سال به سال رو به رشد است و ميزان ابيدمى آن افزايش مىيابد (r). سازمان بهداشت جهانى ديابت را شـايعترين بيمـارى غدد در جهان مىداند كه عامل سالانه ع ميليون مرگ در جهـان اسـت. طبق اطلاعات فدراسيون بين المللى ديابت در سال

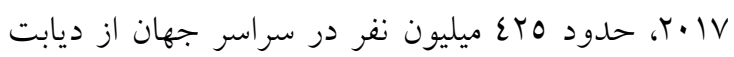

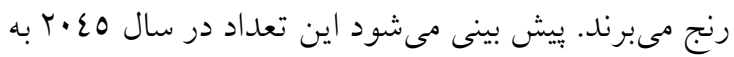
وجا ميليون نفر افزايش يابد. در ايران شيوع ديابت نوع دو 9/7 درصد است و حدود ينج ميليون بزرگسال مبتلا به

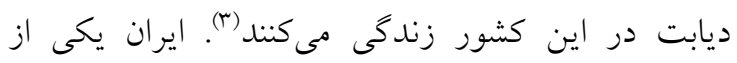
كشورهاى منطقه است كه داراى بالاترين تعداد افراد مبتلا به دبابت است. بيش بينى مىشود تا سال Oع · r اين تعداد

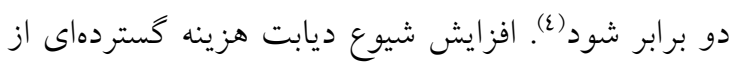
درمان بر فرد، خانواده، جامعه و نظام سلامت تحميل مى كند. ميزان هزينهاى تحميل شده بر سيستم درمانى، براى مراقبتهاى بهداشتى از بيماران مبتلا به ديابت مبلغ قابل توجهى، بالغ بر MTV TMV ميليارد دلار است كه شامل ميليارد دلار هزينه يزشكى مستقيم و •9 ميليارد دلار كاهش بـ بهره ورى تخمين زده مىشود. در ايالات متحده افرادى كه مبتلا به ديابت تشخيص داده شدهاند، هزينه هاى بزشكى آنها به طور متوسط TVO يوند در سال است (0). به طور 
برآورد خود مديريتى و تبعيت دارويى در سـالمندان مبتلا

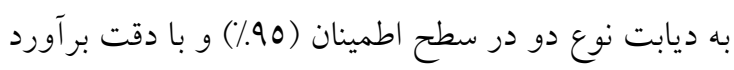

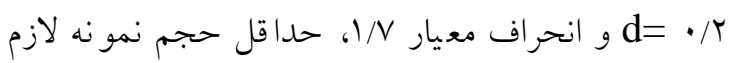

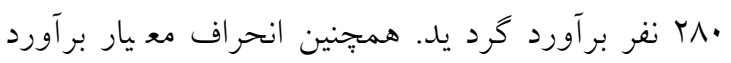

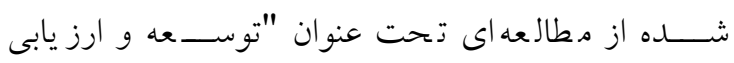
ابزار جSMQ جهت بررسـى فعاليت هاى خودمراقبتى تونى

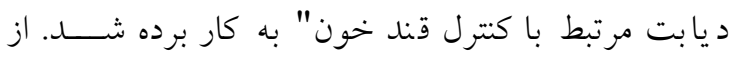

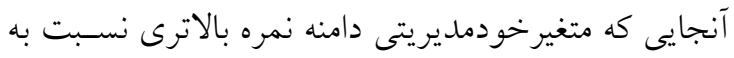
متغير ديخر يزووهش يعنى تبعيت دارويى داشــته، بنابراين از اين متغير براى تعيين حجم نمونه استفاده شد (17).

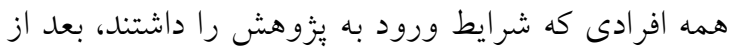

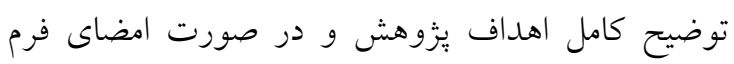
رضايت نامه آكاهانه كتبى در يُزوهش شركت نمودند. معيارهاى ورود به اين مطالعه شامل: ا- داشتن سن بالاى

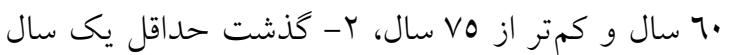
از محرز شدن تشخيص ديابت، ب- تحت درمان با داروهاى

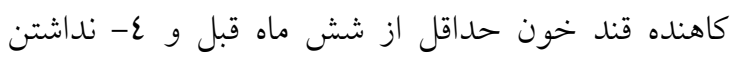

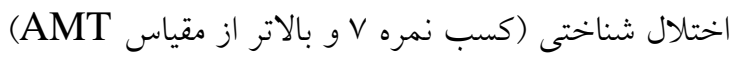
بود. بيمارانى كه شر ايط فوق را دارا نبودند، در مطالعه وارد

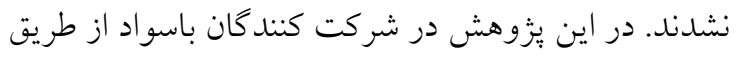

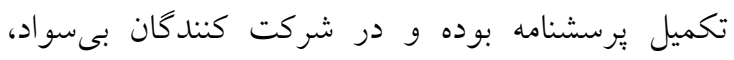

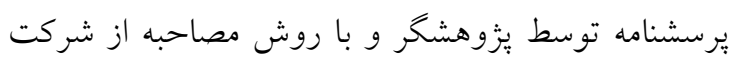

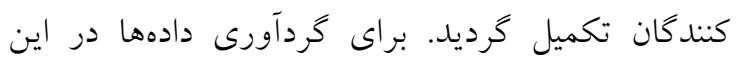
مطالعه از برسشنامه مشخصات جمعيت شناختى استفاده

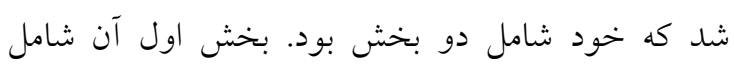

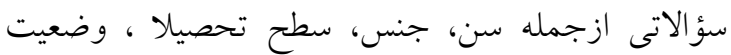

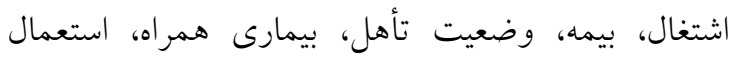
دخانيات، سابقه مصرف دارو، قوميت و بخش دوم شامل

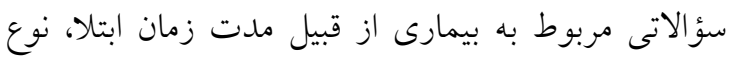

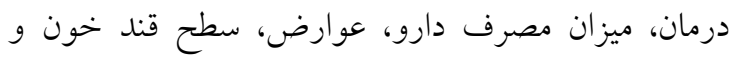

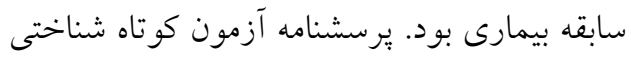
حاوى ده AMT (Abbreviated Mental Test) سؤال است كه جهت ارزيابى وضعيت شناختى سالمندان

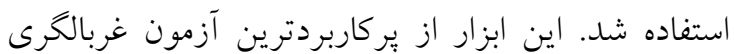

آنها را به خطر انداخته و بر كيفيت كلى زندكى آنان به

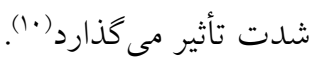
اين امر خصوصاً در بيمارىهاى مزمن كه بيماران بايد مدت تات

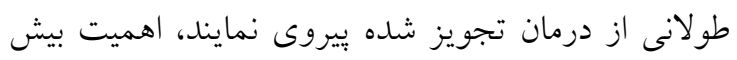

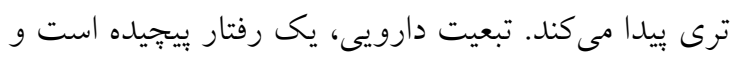

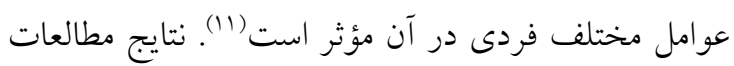
متعدد نشان دادهاند كه تبعيت دارويى در بيماران سالمند مبتلا به ديابت مطلوب نبوده و مى بايست به طور دورهاى

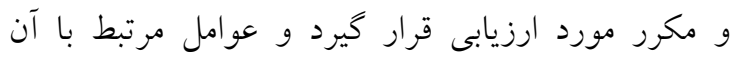
شناسايى شوند (Ir). نتايج مطالعهاى برروى سالمندان مقيم آسايشخاههاى شهر

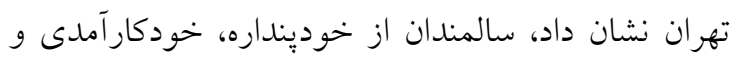
خودمديريتى نامطلوبى برخوردارهستند (rا). هم:جنين نتايج مطالعه ديخرى حاكى از تبعيت ضعيف دارويى در مبتلايان

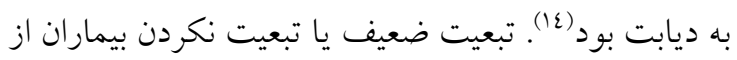

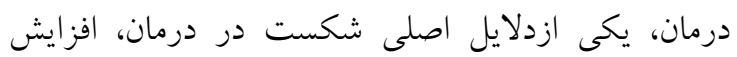
عوارض بيمارى، طولانى شدن مدت درمان و افزايش هزينه

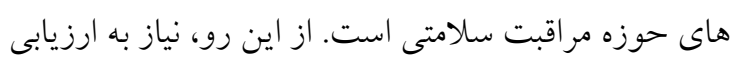

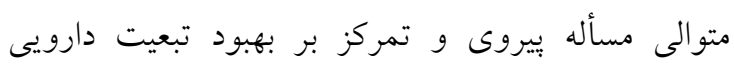

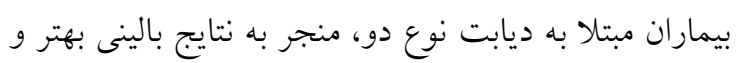
عوارض كمتر در اين بيماران مىشود (10).

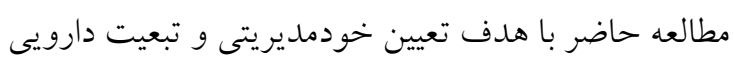

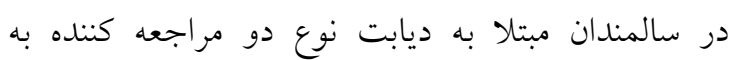

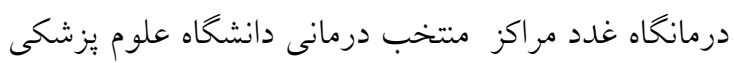

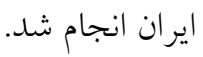

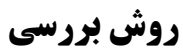

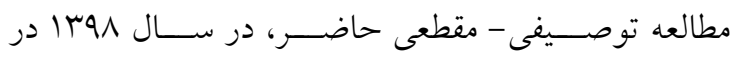

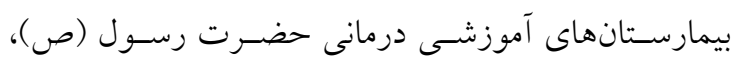

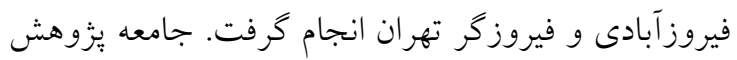

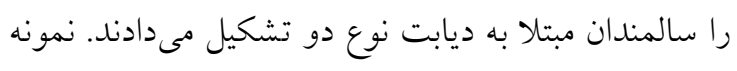
كيرى به روش مـ ستمر از ميان سالمندان مراجعه كننده به ديه

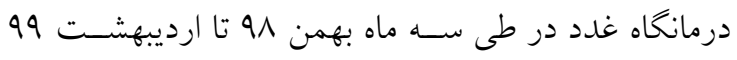
انجام گر فت. جهت تعيين حجم نمو نه لازم به منظور 
در يثزوهش Mehravar و همكاران در سال 17 •r روايى و و إيايى ابزار سنجيده شد.

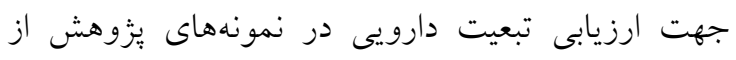
ير سشنامه تبعيت درمانى موريسكى (MMAS) كه در سال

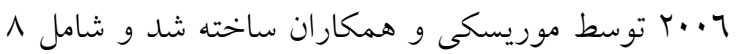

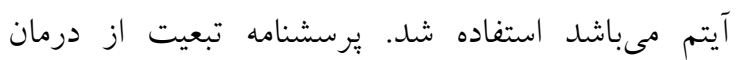
موريسكى داراى هفت كزينه دو نمرهاى (بلى صفر و خير

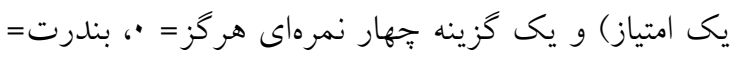

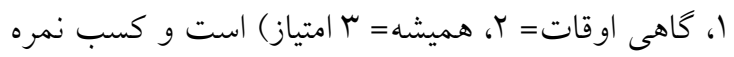

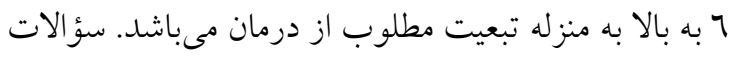

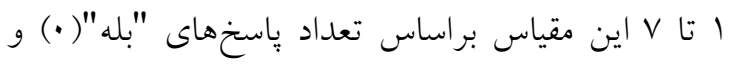

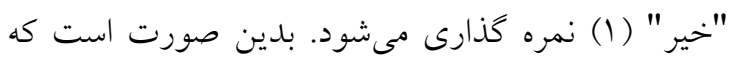

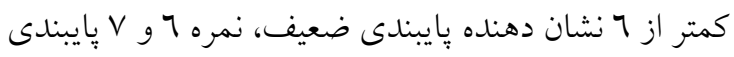

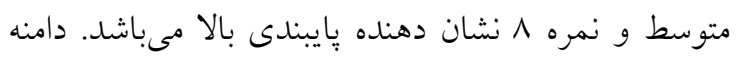

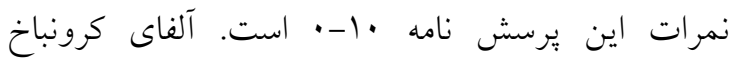

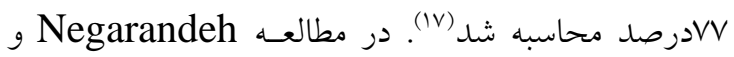

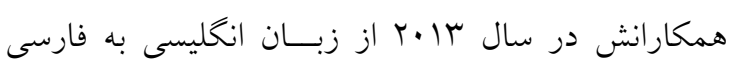

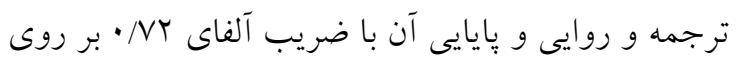

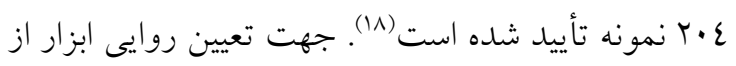

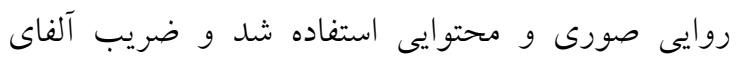

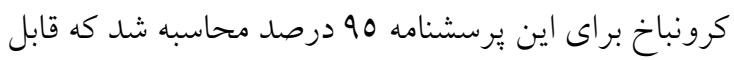

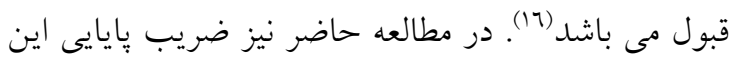

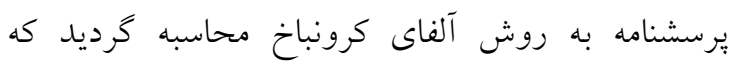

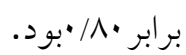

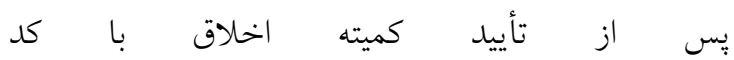

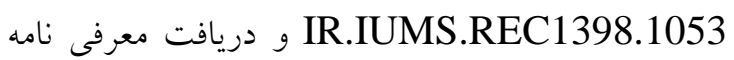

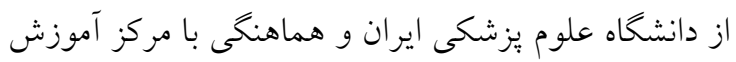
درمانى حضرت رسول (ص)، فيروزگر وفيروزآبادى،

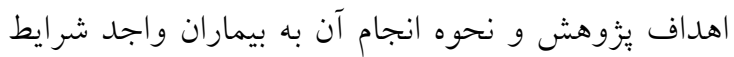

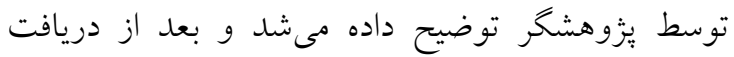
رضايت كتبى بيماران، برسشنامهها توسط بيماران تكميل شد و در مواردى كه سالمند از سواد كافى برخوردار نبود توسط يُزوهشكر تكميل مىشد. تجزيه و تحليل دادهها

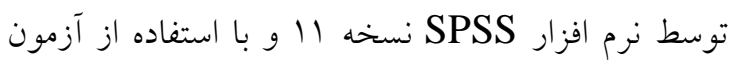

وضعيت شناختى سالمندان در جهان است. اين ابزار در

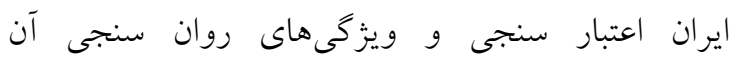

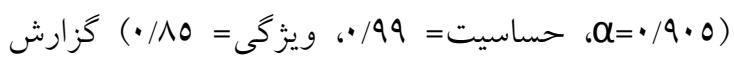
شده است. كسب نمره يايين تر از V در اين آزمون به معنى وجود اختلال شناختى است و بيشترين امتياز آن نمره .

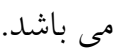
״رسشنامه خودمديريتى ديابت (DSMQ) اين پِرسشنامه

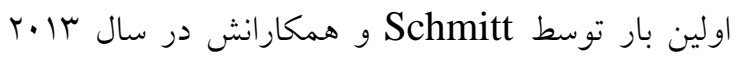
طراحى شده است و با ضريب آلفاكرونباخ عی/• يكى ابزار

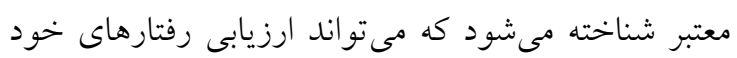

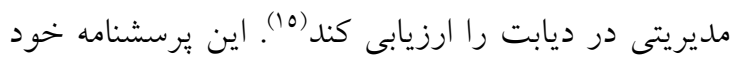

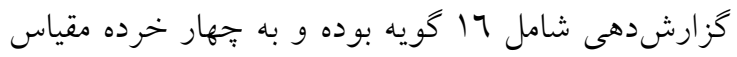

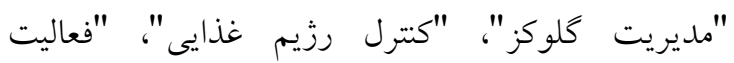

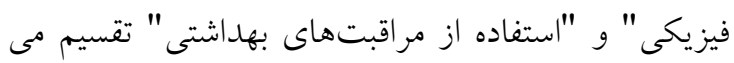

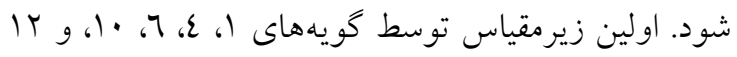

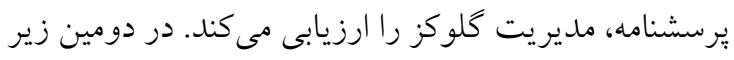

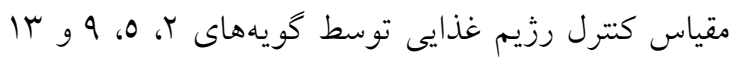

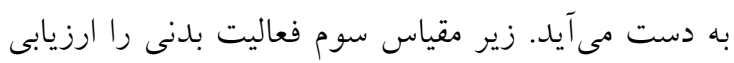

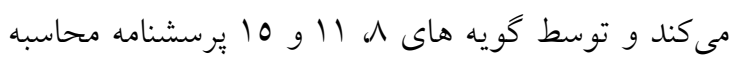

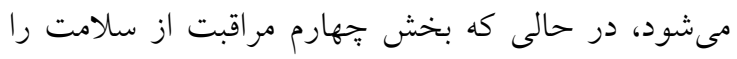

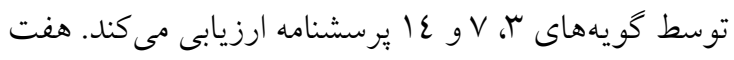

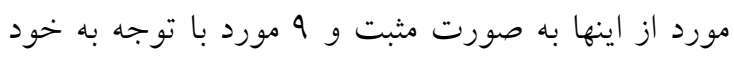

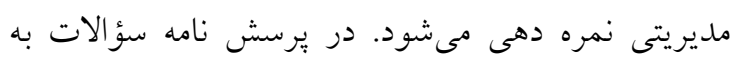

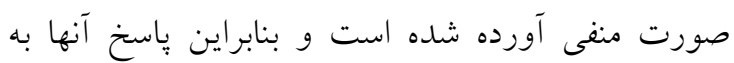

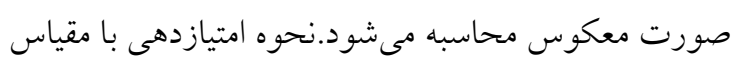

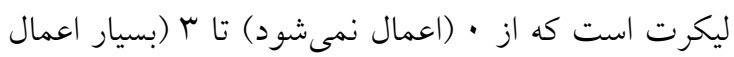

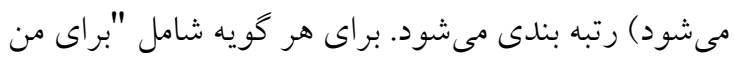

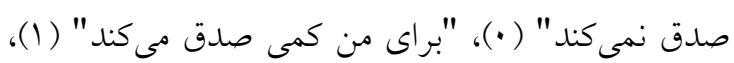

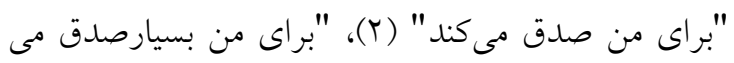

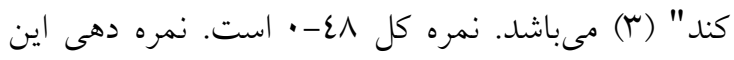
يرسشنامه شامل معكوس كردن موارد منفى است كه نمره بالاتر نشان دهنده خود مديريتى مناسب است. مطالعات بسيارى روايى و يايايى اين ابزار را تأييد كردهاند، براى مثال مئل 
يعنى حدود MV/O درصد افراد BMI< YO داشتند. به منظور شناسايى متغيرهاى تعيين كننده خودمديريتى و ورد تبعيت دارويى در ميان جمعيت مورد مطالعه، اقدام به انجام

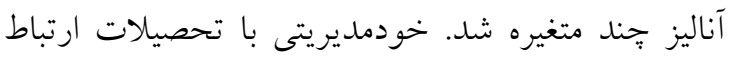

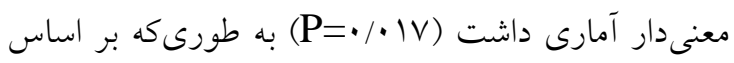

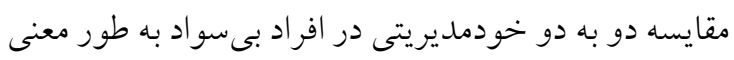

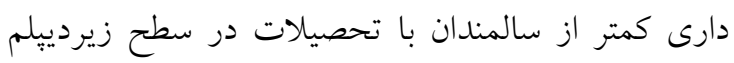
بود. بر اساس نتيجه آزمون تى مستقل

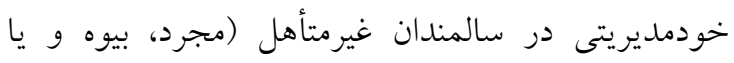
مطلقه) به طور معنىدارى كمتر از سالمندان متأهل بود بودئه

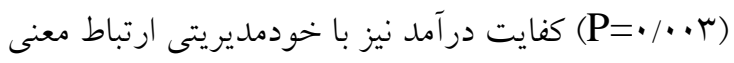

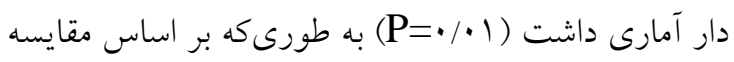
دو به دو آزمون توكى خودمديريتى در سالمندان با درآمد كافى به طور معنى دارى بيشتر از سالمندان با درآمد نسبتًا

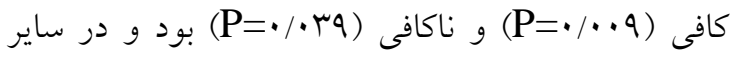
سطوح اين اختلاف معنىدار نبود. تبعيت دارويى در مردان

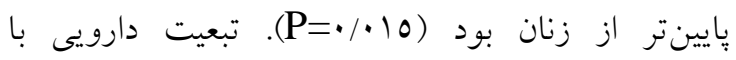

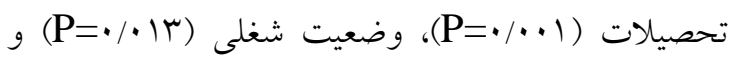

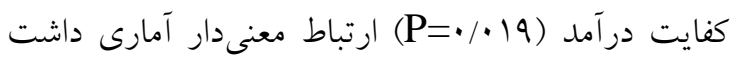

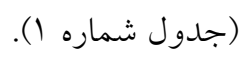

هاى همبستكى ييرسون، اسبيرمن، آناليز واريانس يكطرفه، تى مستقل و تعقيبى توكى انجام شد.

\section{يافتهها} در مطالعه حاضر ميزان پِاسخكويى شركت كنندكان به سوالات ..1 درصد بود. ميانخين سنى سالمندان مورد يُزوهش عُ 7T/7 درصد بود. فراوانى مردان شركت كننده OV/I درصد بيشترين سطح تحصيلى بود. بيشتر واحدهاى مورد

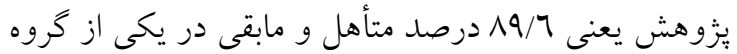
هاى مجرد، مطلقه، يا بيوه قرار داشتند. وضعيت شغلى

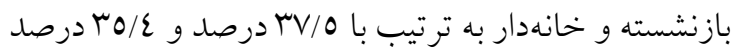

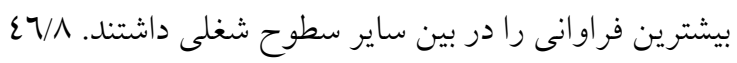

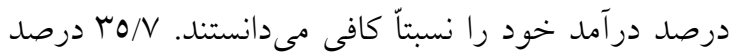
از سالمندان مورد يزووهش بيشتر از بينج سال از زمان ابتلا

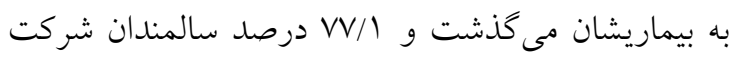
كننده در اين تحقيق واجد حداقل يكى بيمارى همراه بودند

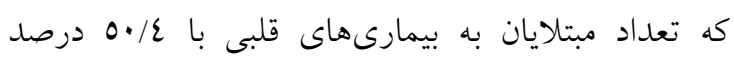
بيشترين مبتلا را در بين بيمارىهاى زمينهاى داشت.

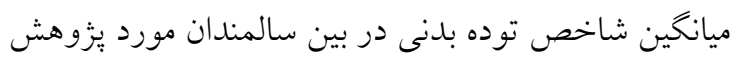

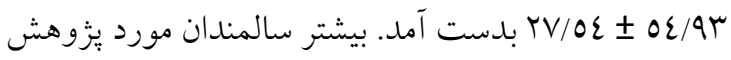

جدول شماره (: بررسى خودمديريتى و تبعيت دارويى سالمندان مبتلا به ديابت نوع دو با متغييرهاى جمعيت شناختى

\begin{tabular}{|c|c|c|c|c|c|c|c|c|}
\hline \multicolumn{3}{|c|}{ تبعيت دارويى } & \multicolumn{3}{|c|}{ خودمديريتى } & \multirow{2}{*}{ فراوانى } & \multirow[t]{2}{*}{ مشخصات فردى } & \\
\hline نتيجه آزمون & معيار & ميانگين & نتيجه آزمون & انحراف & ميانغين & & & \\
\hline${ }^{*} \mathrm{t}=r / \varepsilon r q$ & $r / r$ & $N / T)$ & ${ }^{*} \mathrm{t}=I / \cdot r \mathrm{r}$ & $1 / \wedge 1$ & $7 / 7 V$ & $1 T \cdot(\varepsilon T / 9)$ & زن & \\
\hline$d f=r V I / r q$ & r/ר & $V / \varepsilon q$ & $\mathrm{df}=r \vee \wedge$ & $1 / 00$ & $7 / 27$ & $17 \cdot(0 V / 1)$ & مرد & جنسيت \\
\hline $\mathrm{P}=\cdot / \cdot 10$ & & & $\mathrm{P}=\cdot / \mu \cdot \wedge$ & & & & & \\
\hline \multirow[t]{4}{*}{${ }^{*} \mathrm{P}=\cdot / \cdot \cdot 1$} & r/Ar & T/or & ${ }^{*} \mathrm{P}=\cdot / \cdot 1 \mathrm{~V}$ & $1 / \mu$ & $T \cdot r$ & $O \wedge(Y \cdot / V)$ & بىسواد & \\
\hline & $r / 19$ & $\Lambda / \mu$ & & $1 / 0 T$ & $1 / 7 \varepsilon$ & $11 \cdot(r q / \Gamma)$ & زيردييلم & تحصيلات \\
\hline & $r / 20$ & $V / 91$ & & $1 / 7 r$ & $7 / V V$ & $79(Y \varepsilon / 7)$ & ديبلم & \\
\hline & $r / \varepsilon\rceil$ & $\Lambda / \cdot 7$ & & T/Y & $7 / 7 V$ & $\varepsilon r(10 / \varepsilon)$ & دانشخاهى & \\
\hline${ }^{*} \mathrm{t}=\cdot / 1 \cdot 1$ & $T / T I$ & V/No & ${ }^{*} \mathrm{t}=\mathrm{r} / \cdot 17$ & $1 / V$ & $0 / 7$ & $0(1 / \Lambda)$ & مجرد & \\
\hline $\mathrm{df}=r V \wedge$ & $r / 00$ & $\mathrm{~V} / \mathrm{A}$ & $d f=r \vee \wedge$ & 1/7 & $7 / 70$ & rol $(\wedge 9 / 7)$ & متأهل & وضعيت تأهل \\
\hline $\mathrm{P}=\cdot / 919$ & $T / Y I$ & V/No & $\mathrm{P}=\cdot / \cdot r$ & $1 / V$ & $0 / 7 \Lambda$ & $0(1 / A)$ & مطلقه & \\
\hline
\end{tabular}




\begin{tabular}{|c|c|c|c|c|c|c|c|c|}
\hline & $r / 00$ & $\mathrm{~V} / \mathrm{\Lambda}$ & & 1/7r & $7 / 70$ & $19(7 / 1)$ & بيوه & \\
\hline${ }^{* * *} \mathrm{~F}=r / r \varepsilon r$ & T/VI & $7 / 9$ & ${ }^{* * *} \mathrm{~F}=\cdot / \mathrm{TrV}$ & $1 / 00$ & $T / \pi r$ & $01(1 N / r)$ & آزاد & \\
\hline \multirow{4}{*}{$\mathrm{P}=\cdot / \cdot 1 r$} & $r / \mu r$ & $\tau / \varepsilon$ & $\mathrm{P}=\cdot / \tau r \mathrm{~V}$ & 1/7r & $7 / 20$ & $1 \cdot(r / 7)$ & بيكار & وضعيت شغلى \\
\hline & T/MV & $1 / 11$ & & $1 / 77$ & $\tau / 7 \varepsilon$ & $99(\% 0 / \varepsilon)$ & خانهدار & \\
\hline & T/M & $\wedge$ & & $1 / 7$ & $1 / 7$ & $1.0(r V / O)$ & بازنشسته & \\
\hline & r/Or & $\Lambda / \varepsilon$ & & $r / \Sigma r$ & $\mathrm{~T} / \mathrm{VV}$ & $1.0(\mathrm{rV} / 0)$ & كارمند & \\
\hline \multirow[t]{3}{*}{$P=\cdot / \cdot 19$} & T/IV & N/Or & ${ }^{* * *} \mathrm{~F}=\varepsilon / V Y \varepsilon$ & $r / \cdot r$ & $V / 11$ & $\pi r(r r / l)$ & كافى & \\
\hline & r/OV & $v / \varepsilon q$ & $\mathrm{P}=\cdot / \cdot 1$ & $1 / 29$ & T/ro & $|\Pi|(\varepsilon \tau / \Lambda)$ & نسبتاً كافى & كفايت در آمد \\
\hline & $r / 01$ & $\mathrm{~V} / \mathrm{V} \varepsilon$ & & $1 / 07$ & $7 / \varepsilon \varepsilon$ & $\Lambda V(M I / l)$ & 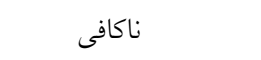 & \\
\hline $\mathrm{t}=\mathrm{r} / \wedge \vee_{0}$ & $r / 01$ & $V / / \varepsilon$ & ${ }^{*} \mathrm{t}=r / \cdot \varepsilon r$ & IVY & $T / Y \varepsilon$ & $\Lambda r(r q / 7)$ & كمتر از 1 & مدت زمان ابتلاى به \\
\hline $\mathrm{df}=r \vee \wedge$ & $r / \varepsilon 0$ & $\Lambda / \wedge$ & $\mathrm{df}=r \vee \wedge$ & $1 / 7 r$ & $T / 7$ & $q V(r \varepsilon / v)$ & بين ا تا ه & بيمارى(سال) \\
\hline $\mathrm{P}=\cdot / \cdot \varepsilon$ & T/OV & $V / \varepsilon q$ & $\mathrm{P}=\cdot / \cdot \varepsilon r$ & $1 / 29$ & T/ro & $\cdots(r \circ / N)$ & بالاتر از 0 & \\
\hline$* t=r / \cdot \eta \Lambda$ & $r / 27$ & $V / 9 V$ & $\mathrm{t}=\cdot / \cdot 7 r$ & $1 / 7 \varepsilon$ & $7 / 00$ & $r / 7(V V / I)$ & بله & \\
\hline $\mathrm{df}=r \vee \wedge$ & $r / 7 \varepsilon$ & $V / r \mu$ & $\mathrm{df}=r \vee \wedge$ & $1 / v \varepsilon$ & T/OL & $T \varepsilon(Y r / Q)$ & خير & بيمارى هاى همراه \\
\hline $\mathrm{P}=\cdot / \cdot \varepsilon$ & & & $\mathrm{P}=\cdot / 901$ & & & & & \\
\hline$" t=\cdot / 79 r$ & $T / V$ & $N / \cdot \varepsilon$ & ${ }^{*} \mathrm{t}=\cdot / 0 \mathrm{Vq}$ & INT & $T / \Sigma T$ & $\varepsilon \varepsilon(10 / v)$ & يوكى بله & \\
\hline$d f=r \vee \wedge$ & $r / 2 q$ & V/NO & $d f=r \vee \wedge$ & $1 / 70$ & T/OV & r & استخوان & \\
\hline $\mathrm{P}=\cdot / \varepsilon \wedge q$ & & & $\mathrm{P}=\cdot / 07 \pi$ & & & & & \\
\hline${ }^{*} \mathrm{t}=Y / \Gamma Y T$ & $T / M T$ & $N / 1 \varepsilon$ & ${ }^{\mathrm{t}} \mathrm{t}=\cdot / \mathrm{orV}$ & $1 / 79$ & $7 / 7$ & $|\varepsilon|(0 \cdot / \varepsilon)$ & بيمارىهاى بله & \\
\hline $\mathrm{df}=r \vee \wedge$ & $r / 7 V$ & $V / \varepsilon O$ & $\mathrm{df}=r \vee \wedge$ & 1/7 & $7 / 0$ & $1 \% 9(\varepsilon 9 / 7)$ & ق ق & نوع بيمارى \\
\hline $\mathrm{P}=\cdot / \cdot r \mid$ & & & $\mathrm{P}=\cdot / 091$ & & & & & \\
\hline $\mathrm{t}=\cdot \Gamma \wedge 1$ & $r / \varepsilon \wedge$ & $V / 77$ & $\mathrm{t}=\cdot / T 17$ & $1 / 00$ & $7 / 0$ & $\sum r(10)$ & بيمارىهاى بله & \\
\hline$d f=r \vee \wedge$ & r/Or & V/AT & $d f=r \vee \wedge$ & $1 / 71$ & $7 / 07$ & 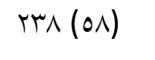 & كليوى & \\
\hline $\mathrm{P}=\cdot / V \cdot r$ & & & $\mathrm{P}=\cdot /$ Arq & & & & & \\
\hline${ }^{*} \mathrm{t}=r / \varepsilon \cdot V$ & $T / M V$ & N/TO & $\mathrm{t}=1 / 17 \varepsilon$ & $1 / 7 \pi$ & $7 / \mathrm{V}$ & $1 \cdot V(r \Lambda / Y)$ & بيمارىهاى بله & \\
\hline $\mathrm{df}=r \mu \wedge / \varepsilon \wedge$ & $r / O V$ & V/Or & $d f=r \vee \wedge$ & $1 / 71$ & $T / 27$ & $\operatorname{IVT}(7 \mid / \Lambda)$ & جشمى خير & \\
\hline $\mathrm{P}=\cdot / \cdot 1 \mathrm{~V}$ & & & $\mathrm{P}=\cdot / r\{\rceil$ & & & & & \\
\hline${ }^{*} \mathrm{t}=r / 7 \mu \mathrm{I}$ & $r / 77$ & $7 / \pi 1$ & ${ }^{*} \mathrm{t}=r / \cdot q$ & $1 / 40$ & $O / V$ & rT (11/2) & بيمارىهاى بله & \\
\hline $\mathrm{df}=r \vee \wedge$ & $T / V$ & $\Lambda / \cdot \varepsilon$ & $\mathrm{df}=r \vee \wedge$ & $1 / 71$ & $7 / 77$ & $r \Sigma \wedge(\Lambda \Lambda / \tau)$ & ريوى & \\
\hline $\mathrm{P}=\cdot / \cdot r$ & & & $\mathrm{P}=\cdot / \cdots r$ & & & & & \\
\hline${ }^{*} \mathrm{t}=1 / \Gamma \mid r$ & $r / T \Lambda$ & $V / \neg \varepsilon$ & $\mathrm{t}=\cdot / \mathrm{N} / \mathrm{r}$ & $1 / 7 T$ & $7 / 71$ & $\operatorname{IV}(7 T / 1)$ & دارد & سابقه خانو ادگى ابتلا به \\
\hline $\mathrm{df}=r \diamond \varepsilon / \varepsilon \wedge$ & $r / T)$ & $\Lambda / \cdot 0$ & $\mathrm{df}=r \vee \wedge$ & $1 / N r$ & $T / 20$ & $1 \cdot 7(r V / q)$ & 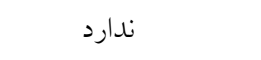 & ديابت \\
\hline $\mathrm{P}=\cdot / / \mathrm{V}$ & & & $\mathrm{P}=\cdot / \varepsilon \mid V$ & & & & & \\
\hline
\end{tabular}

\begin{tabular}{|c|c|c|c|c|c|c|}
\hline $\mathrm{r}=-\cdot / \mu \mathrm{TV}$ & $\mathrm{P}<\cdot / \cdot \cdot \mid$ & $\mathrm{r}=-\cdot / \mu T_{1}$ & $\mathrm{P}=\bullet / \cdot \cdot 1$ & $T / V T \pm r / 99$ & انحراف معيار 土 ميانگين & 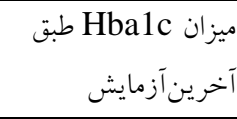 \\
\hline $\mathrm{r}=-\cdot / r q \mu$ & $\mathrm{P}<\bullet / \cdots 1$ & $\mathrm{r}=-\cdot / r Y r$ & $\mathrm{P}<\cdot / \cdots+1$ & $\begin{array}{l}v 7 / 91 \\
19 N / T 0 \pm\end{array}$ & انحراف معيار 土 ميانخين & ميزان سطح قند خون آخرين آزمايش \\
\hline$r=-.1 .00$ & $\mathrm{P}=\cdot / \pi 00$ & $\mathrm{r}=-. \cdot 1 \cdot 91$ & $\mathrm{P}=\cdot / 1 \cdot 1$ & $77 / 7 \varepsilon \pm \varepsilon / 91$ & انحراف معيار 土ـميانخين & سن \\
\hline $\mathrm{r}=-\cdot / \cdot \mathrm{v}\urcorner$ & $\mathrm{P}=\cdot / T \cdot 0$ & $\mathrm{r}=-\cdot / \mathrm{IV}$ & $\mathrm{P}=\cdot / \cdots \varepsilon$ & TV/OE $\pm 0 / 9 T$ & انحراف معيار 土 ميانخين & شاخص توده بدنى \\
\hline
\end{tabular}


را در بين ساير ابعاد داشتند. نتايج نشان داد كه ميانخين

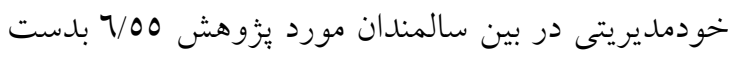

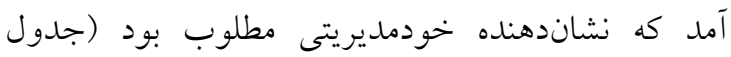

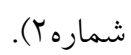

با توجه به اين كه زير مقياسهاى خودمديريتى شامل

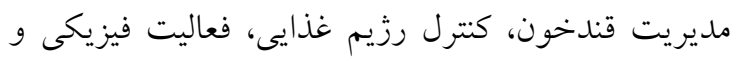

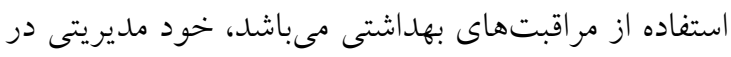

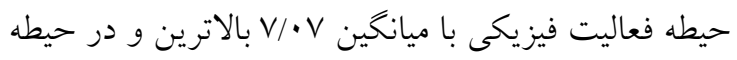

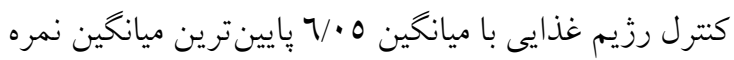

جدول شمارهץ: شاخصهاى عددى خود مديريتى در سالمندان مبتلا به ديابت نوع دو

\begin{tabular}{|c|c|c|c|c|c|c|c|c|}
\hline \multicolumn{4}{|c|}{ بر مبناى · تا · } & \multirow[t]{2}{*}{ انحر اف معيار } & \multirow[t]{2}{*}{ ميانگين } & \multirow[t]{2}{*}{ بيشينه } & \multirow[t]{2}{*}{ 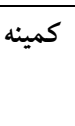 } & \multirow[t]{2}{*}{ خود مديريتى و حيطه هاى آن } \\
\hline انحر اف معيار & ميانغين & بيشينه & كمينه & & & & & \\
\hline$T / \cdot 7$ & $7 / \mathrm{NV}$ & 1. &.$/ 7 \mathrm{~V}$ & $r / 1$ & 1.110 & 10 & 1 & مديريت كلوكز (10-•) \\
\hline r/07 & $7 / 0$ & 1. & . & $r / \cdot v$ & $V / T V$ & ir & - & كتترل رزيم غذايى (rا-•) \\
\hline$r / T r$ & $v / \cdot v$ & 1. & . & $r / M T$ & $7 / \pi 7$ & 9 & . & فعاليت فيزيكى (9-•) \\
\hline$r / \mu$ & $7 / 27$ & 1. & . & $r / 1$ & $0 / \wedge 1$ & 9 & . & استفاده از مر اقبتهاى بهداشتى (9-•) \\
\hline $1 / 77$ & $7 / 00$ & 1. & $1 / 40$ & $\wedge$ & $\mu_{1 / \varepsilon 7}$ & $\varepsilon \wedge$ & 7 & خود مديريتى (^乞-•) \\
\hline
\end{tabular}

هايِين بود كه مىتواند با كنترل قند خون، فعاليت بلنى نامناسب و رعايت نكردن رزيم غذايى ارتباط داشته

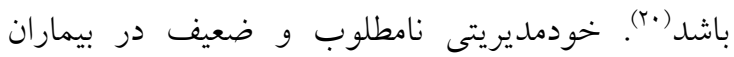
ديابتيك با عوارض جدى همراه بوده و در اين راستا

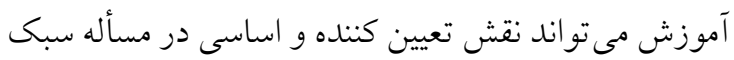

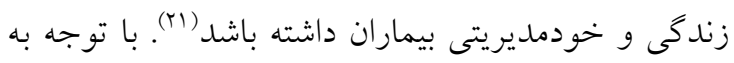
اين كه زير مقياسهاى خودمديريتى شامل مديريت قندخون، كنترل رزيم غذايى، فعاليت فيزيكى و استفاده از مراقبت هاى بهداشتى مىباشد، مشاهده شد سالمندان مبتلا به ديابت در حيطه فعاليت فيزيكى بالاترين نمره را داشتند.

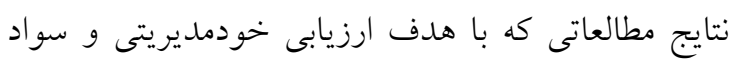
سلامت در مبتلايان به ديابت انجام شد، نشان داد بيماران

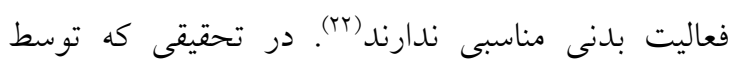
Becker و همكارانش كه با هدف تعيين ارتباط بين رفتار خودمديريتى و ويزَكىهاى اجتماعى و جمعيتى مربوط به بيمارى در سالمندان مبتلا به ديابت نوع دو انجام شد، لع

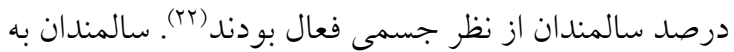
دليل مشكلات فيزيكى، بيمارىها و ناتوانىها غالباً

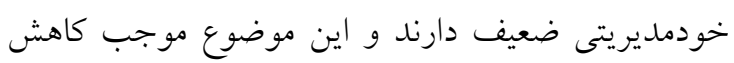

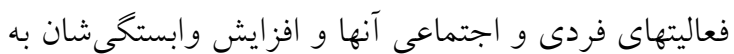

نتايج نشان داد كه ك/rT درصد از واحدهاى مورد يززوهش

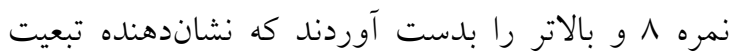

$$
\text { دارويى مطلوب بود (جدول شماره ب). }
$$

جدول شمارهr: شاخصهاى عددى تبعيت دارويى در سالمندان مبتلا به ديابت نوع دور سمار سوح

\begin{tabular}{|c|c|c|}
\hline درصد & فر اوانى & تبعيت دارويى \\
\hline$\% / r Y / \varepsilon$ & 7. & ضعيف (كمتر از 7) \\
\hline$\% 10 / \varepsilon$ & $\varepsilon r$ & متوسط (V-V) \\
\hline$\% \pi r / r$ & IVV & بالا (^ و بالاتر) \\
\hline$\% 1 \cdots$ & rA. & جمع كل \\
\hline \multicolumn{2}{|c|}{$V / \Lambda \pm r / O r$} & انحراف معيار 土 ميانگين \\
\hline
\end{tabular}

\section{بحث و نتيجه كيرى}

مطالعه حاضر به منظور بررسى تعيين خودمديريتى و تبعيت دارويى در سالمندان مبتلا به ديابت نوع دو مراجعه كننده به درمانگاه غدد مراكز منتخب درمانى دانشخاه علوم يزشكى ايران در سال ^هץ| برنامه ريزى و انجام گرديد.

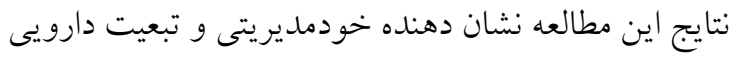
مطلوب سالمندان مورد يزوهش بود. در مطالعه Tuncay و همكارانش بيماران خودمديريتى متوسطى داثتند (19).

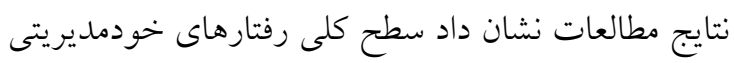


Xu و همكاران نشان دادكه سطح تحصيلات و داشتن شغل

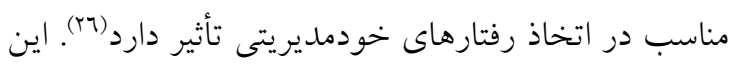
يافتها با نتيجه مطالعه حاضر همسو مىباشند.

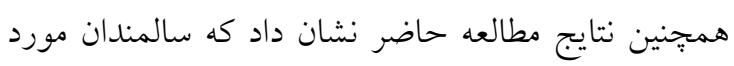
يزوهش تبعيت دارويى مطلوب داشتند. در همين راستا نتايج مطالعهاى توسط Ranjbaran و همكارانش در سال

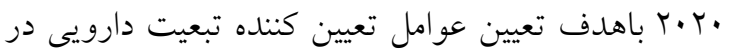

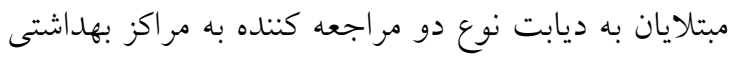
و درمانى جنوب تهر ان نشان داد، تبعيت دارويى در مبتلايان به ديابت نوع دو ضعيف بوده و همبستخى معنى دارى بين

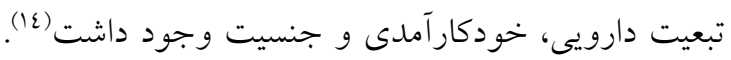
دشتيان و همكاران در يزوهش خود به بررسى عوامل مرتبط با تبعيت دارويى و ميزان فعاليت جسمانى درمبتلايان به

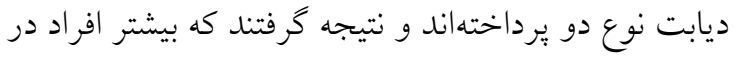
اين يزوهش از تبعيت دارويى خوبى برخوردار بوده و از

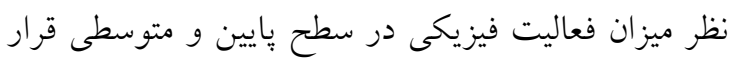

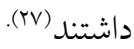
همجنين از ميان تمامى عوامل دموكرافيك مورد بررسى، فاكتورهايى جون جنسيت، سطح تحصيلات، كفايت درآمد و وضعيت شغلى با تبعيت دارويى ارتباط معنى دار داشتند. در مورد سطح تحصيلات، تبعيت دارويى با تحصيلات

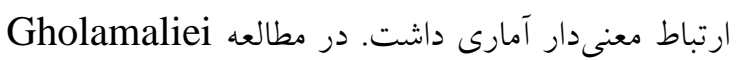

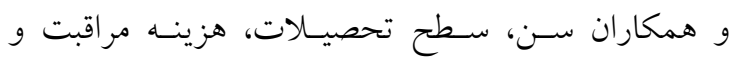

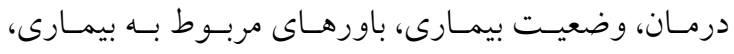

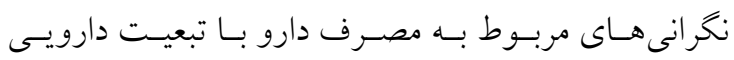

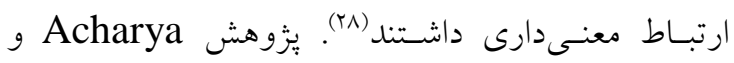
همكاران نشان داد كه سطح تحصيلات، سن و طول مدت

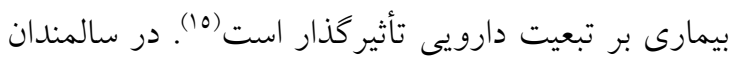

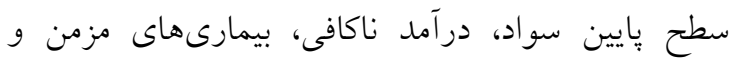
اختلالات شناختى شايعتر است. در نتيجه اين افراد به عنوان كروههاى در معرض خطر جامعه نياز به توجه

$$
\text { بيشترى دارند. }
$$

در رابطه با كفايت درآمد، خودمديريتى با كفايت درآمد

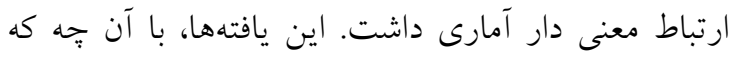

ديخران مىشود كه اين خود باعث بدترشدن وضعيت

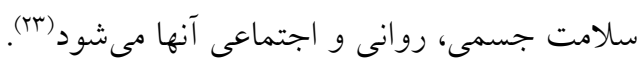

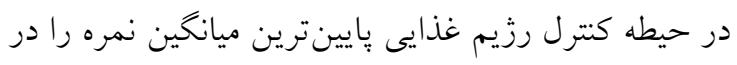

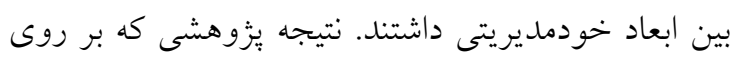

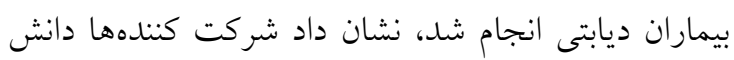
ضعيفى در موردرعايت رزيم غذايى داشتند (19). در مطالعه دئل از 7 Werfalli درصد برنامه غذايى ديابتيك را رعايت مىكردند (ع). رزيم غذايى سالم، افزايش فعاليت بدنى و كاهش وزن ندابنه نه تنها باعث مديريت HbA1c بلكه خطر بيمارىهاى قلبى و و عروقى را كاهش مىدهد. كاهش احساس جشايى و بويايى، از دست دادن دندانها يا دندان مصنوعى نامناسب،

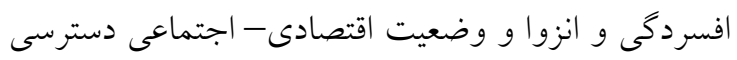

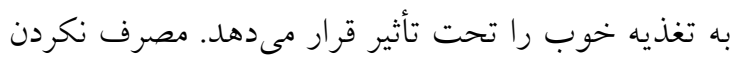

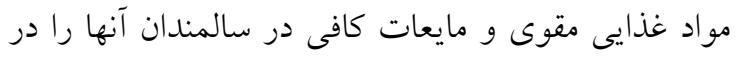
معرض خطر بيشترى قرار مىدهد (·r). با توجه به مائه اينكه

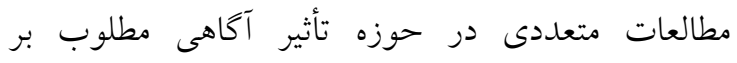
ويامدهاى بيمارى ديابت به انجام رسيده است، جاى هيج

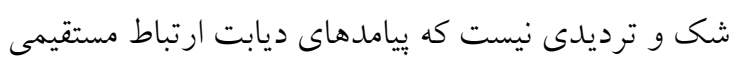

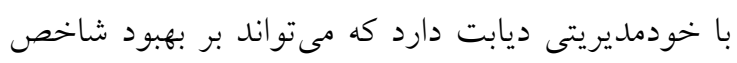

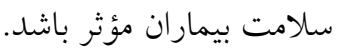

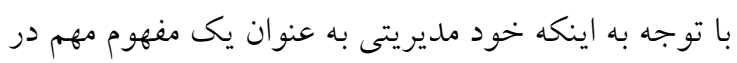

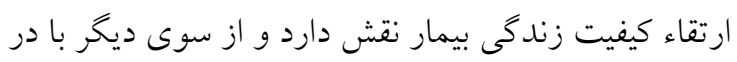
نظر كرفتن نقش فعال و مشاركت بيماران سالمند در فر آيند

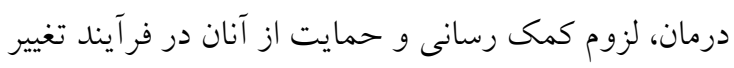
رفتار مهمترين عامل تعيين كننده كنترل بيمارى ديابت مى

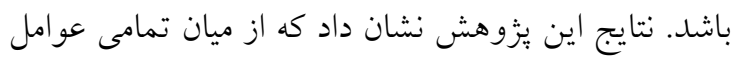
جمعيت شناختى مورد بررسى، فاكتورهايى خجون سطح

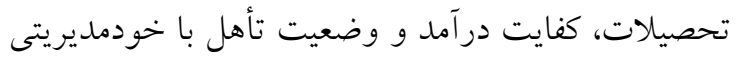

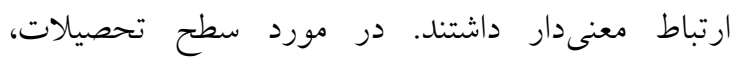
خودمديريتى با تحصيلات ارتباط معنىدار آمارى داشت.

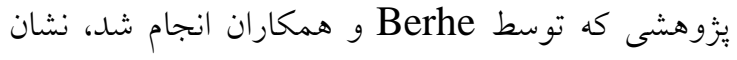

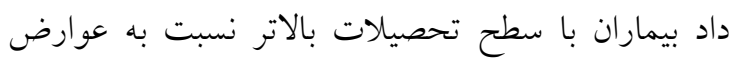

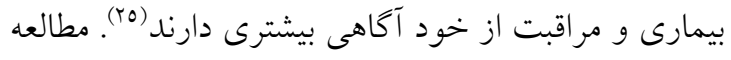


مصرف دارو به دليل مشغله زياد استرس بالاى كار با اتخاذ

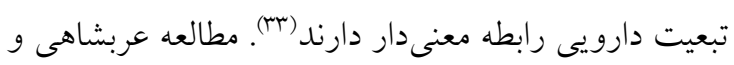
همكاران نشان داد تبعيت از رزيم دارويى در افراد با شغل آزاد بيشتر مىباشد؛ اما مديريت وزن در كارمندان مناسب تر مىباشد(ז). جنسيت متغير ديخرى بود كه با تبعيت دارويى ارتباط معنىدار داشت، به طوريكه تبعيت دارويى ليى در مردان به طور معنى دارى بايينتر از زنان بود. با اين حال، مطالعات صورت يذيرفته بر روى بيماران مبتلا به ديابت نتايج كاه ضد و نقيضى از اين نظر به همراه داشتهاند. برخى جون تنهارو وهمكاران كزارش كردند خانمها نسبت به آقايان از تبعيت دارويى بالاترى برخوردار بودند(ro). نتايج برخى ديخر از مطالعات نشان داده است كه خود مديريتى نامطلوب و عدم تبعيت از يروتوكل هاى درمانى در بيماران ديابتيك و اختلالات كبدى با عوارض جدى مراجعه كنندكان بخشهاى اورزانس همراه بوده و در اين راستا عملكرد مناسب و مطلوب بيماران در خصوص سبك عـ رك زندكى بهداشتى و خودكار آمدى بيماران در خود مديريتى

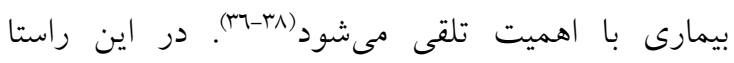
مداخلات آموزش بهداشت در كتترل داشتن بيماران بر وضعيت سلامتى و خودكارآمدى مىتواند نقش تعيين كنندهاى داشته باشد (ra). بنابراين به نظر مىرسد از محدوديت اين مطالعه مىتوان به تكميل برسش نامهها به شيوه خودگز ارشى براى بيماران با سواد و مصاحبه توسط يرسشخران آموزش ديده براى بيماران بى سواد اشاره نمود. به علاوه با توجه به اينكه شركت كنند گان در مطالعه حاضر، به شيوه نمونه كيرى غير تصادفى در دسترس انتخاب شدند، ممكن است نتايج مطالعه حاضر به كل بيماران ديابتى نوع دو قابل تعميم نباشد. بنابراين مىتوان عوارض نامطلوب ديابت با. مداخلات و اتخاذ مؤثر رفتارهاى خودمديريتى و تبعيت دارويى كاهش يافته و بروز آنها به تأخير افتد. نتيجه نهايى اين مطالعه نشان داد خود مديريتى و تبعيت دارويى در سالمندان مبتلا به ديابت نوع دو مراجعه كننده به درمانگاههاى غدد در سطح مطلوب بود كه با عنايت به
دربرخى يزووهشهاى ييشين يافت شده همخو انى دارند (1). برخى يزوهشخران معتقدند كمبود منابع مالى، فقدان حمايت خانواده و دوستان، باورهاى فرهنكى و سواد بهاشتى بايين بر خودمديريتى بيماران مبتلا به ديابت تأثير

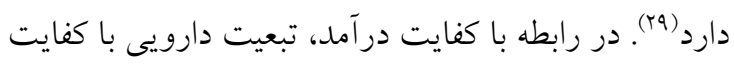
درآمد ارتباط معنى دار آمارى داشت. مطالعه نادرى روش و همكاران نشان داد متغيرهايى جون سطح تحصيلات، داشتن شغل و كفايت درآمد بر تبعيت دارويى تأثير كذار هستند(·r). نتايج اين مطالعه در تأييد مطالعه سجادى و همكاران هستند كه محل زندگى، سن و درآمد بيمار

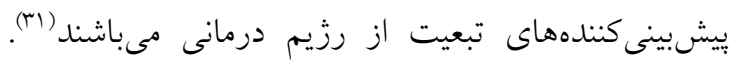
كروههاى كم درآمد اجتماع به دليل فقدان برخوردارى از حمايت مالى و عاطفى رفتارهاى خودمديريتى و تبعيت دارويى رادر حد بسيار پايين نشان مىدهند زيرا در برآورده سازى نيازهاى اولىتر خود ماندهاند. بنابراين رويكردهاى متنوعى در ارتقاء رفتارهاى خود مديريتى ديابت وجود دارد كه موجب بهبود كيفيت زندگى، كنترل متابوليك و شاخص هاى بالينى بيماران مى گردد. در مطالعه حاضر وضعيت تأهل متغير ديخرى بود كه با خودمديريتى ارتباط معنى دار آمارى داشت. نتايج تحقيقات كه توسط Tol و همكاران انجام شد نشان داد كه عوامل جمعيت شناختى مانند: سن، جنس، وضعيت تأهل و سطح تحصيلات با اتخاذ رفتارهاى خودمديريتى رابطه معنىدار دارند(rr).تحقيقات نشان داده عواملى جِون سن، جنسيت و وضعيت تأهل برفعاليتهاى خودمديريتى تأثير به سزايى

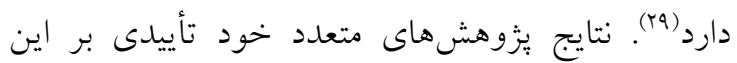
مطلب مىباشد كه بيمارانى كه حمايت بيشترى را از جانب شبكه خانواده خود دريافت مىكنند از خودمديريتى مطلوبى برخوردار هستند. در اين مطالعه وضعيت شغلى با تبعيت دارويى ارتباط معنى دار داشت. نتايج تحقيقات نشان دهنده آن بود كه رعايت نكردن رزيم درمانى به دليل شرايط نامناسب كارى، نداشتن زمان كافى براى غذا خوردن در محل كار، سخت بودن تطابق با درمان به دليل نوع شغل، فراموش كردن زمان 


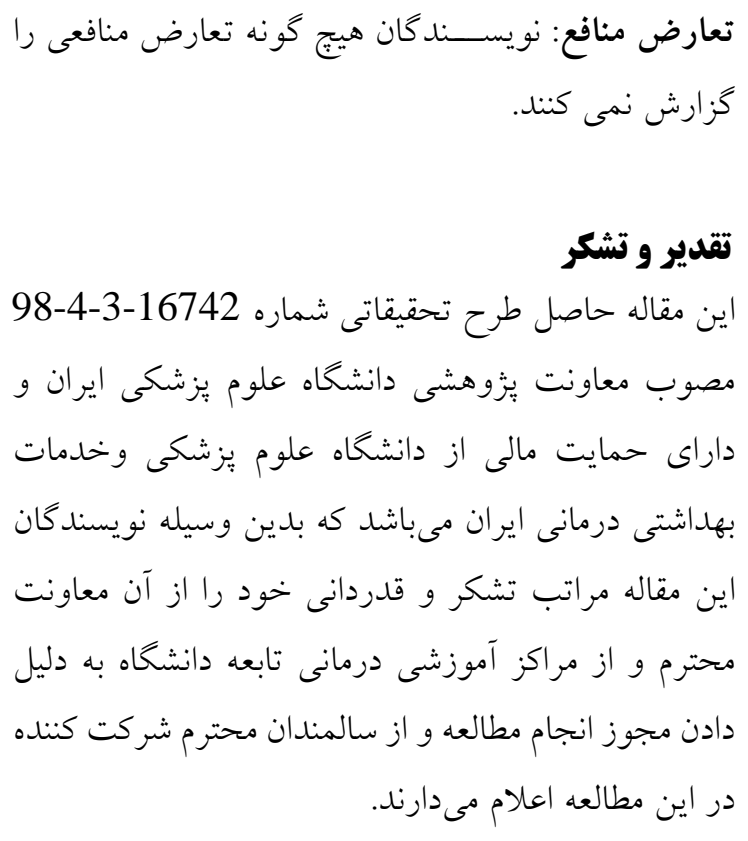$$
\text { در اين مطالعه اعلام مىدارند. }
$$

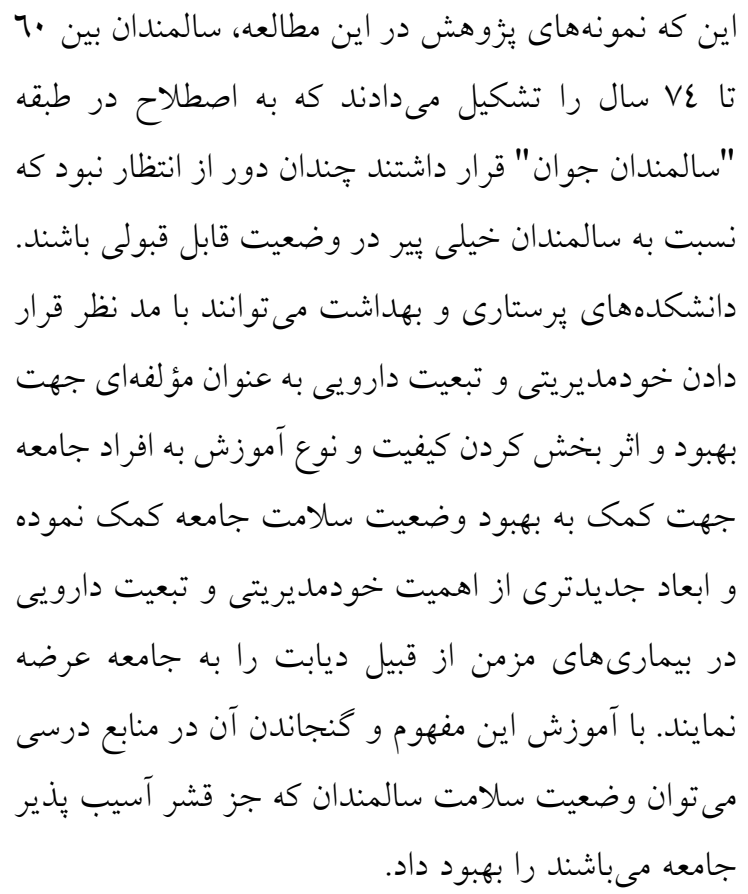

\section{References}

1. WHO. Ageing and Health Key Facts 2018 [cited 201818 Desember]. Available from: https://www.who.int/news-room/fact-sheets/detail/ageing-and-health.

2. Cho N, Shaw JE, Karuranga S, Huang Y, da Rocha Fernandes JD, Ohlrogge AW, Malanda B. IDF Diabetes Atlas: Global estimates of diabetes prevalence for 2017 and projections for 2045. Diabet Res Clin Pract. 2018;138:271-81.

3. Sicree R, Shaw J, Zimmet P, Heart BI. The global burden. Diabetes and impaired glucose tolerance Baker IDI Heart and Diabetes Institute. 2010. (Accessed May 2012) http://www.idf.org/ diabetesatlas/5e/the- global-burden.

4. Ogle GD, Middlehurst AC, Silink M. The IDF Life for a Child Program Index of diabetes care for children and youth. Pediatric diabetes. 2016;17(5):374-84.

5. Guénette L, Lauzier S, Guillaumie L, Giguère G, Grégoire JP, Moisan J. Patients' beliefs about adherence to oral antidiabetic treatment: a qualitative study [Corrigendum]. Patient Prefer Adher. 2017;11:1709-10.

6. Piroozi B, Mohamadi-Bolbanabad A, Moradi G, Safari H, Ghafoori S, Zarezade Y, Bidarpour F, Rezaei S. Incidence and intensity of catastrophic health-care expenditure for Type 2 diabetes mellitus care in iran: determinants and inequality. Diabetes, Metabolic Syndrome and Obesity: Targets and Therapy. 2020;13:2865.

7. Rwegerera GM, Moshomo T, Gaenamong M, Oyewo TA, Gollakota S, Mhimbira FA, Fadare J, Godman B, Meyer JC, Rivera YP. Retracted Article: Antidiabetic medication adherence and associated factors among patients in Botswana; implications for the future. Alexand J Medic. 2018;54(2):103-9.

8. World Health Organization. Noncommunicable diseases: Progress monitor 2020. World Health Organization; 2020.

9. Aghayosefi A, Alipour A, Rahimi M, Abaspour P. Investigation of the efficacy of acceptance and commitment therapy (ACT) on psychological indices (Stress, quality of life, and coping strategies) among the patients with type II diabetes. Journal of Isfahan Medical School. 2018;35(461):185966. [Persian]

10. ARd M, Álvares J, Diniz LM. Ruberson Ribeiro da Silva M., Alvernaz dos Santos BR, Guerra Junior AA, Cherchiglia ML, Andrade EIG, Godman B., Acurcio FdA. Quality of life of patients with diabetes mellitus types 1 and 2 from a referal health centre in minas gerais, Brazil. Expet Rev. Clin. Pharmacol. 2016;9:739-46. 
11. Car J, Tan WS, Huang Z, Sloot P, Franklin BD. eHealth in the future of medications management: personalisation, monitoring and adherence. BMC medicine. 2017;15(1):1-9.

12. Guénette L, Lauzier S, Guillaumie L, Giguère G, Grégoire JP, Moisan J. Patients' beliefs about adherence to oral antidiabetic treatment: a qualitative study. Patient Prefer Adher. 2015;9:413.

13. Kahe M, Vameghi R, Foroughan M, Bakhshi E, Bakhtyari V. The relationships between selfconcept and self-efficacy with self-management among elderly of sanatoriums in Tehran. Iranian Journal of Ageing. 2018;13(1):28-37. [Persian]

14. Ranjbaran S, Shojaeizadeh D, Dehdari T, Yaseri M, Shakibazadeh E. Determinants of medication adherence among Iranian patients with type 2 diabetes: An application of health action process approach. Heliyon. 2020;6(7):e04442.

15. Acharya AS, Gupta E, Prakash A, Singhal N. Self-reported Adherence to Medication among Patients with Type II Diabetes Mellitus attending a Tertiary Care Hospital of Delhi. J Assoc Physic India. 2019;67(4):26-9.

16. Schmitt A, Gahr A, Hermanns N, Kulzer B, Huber J, Haak T. The Diabetes Self-Management Questionnaire (DSMQ): development and evaluation of an instrument to assess diabetes self-care activities associated with glycaemic control. Health Quality Life Outcom. 2013;11(1):1-4.

17. Morisky DE. Predictive validity of a medication adherence measure for hypertension control. J Clin Hyperten. 2008;10:348-54.

18. Negarandeh R, Mahmoodi H, Noktehdan H, Heshmat R, Shakibazadeh E. Teach back and pictorial image educational strategies on knowledge about diabetes and medication/dietary adherence among low health literate patients with type 2 diabetes. Primary care diabetes. 2013;7(2):111-8.

19. Tuncay FÖ, Avc1 D. Association between self-care management and life satisfaction in patients with diabetes mellitus. Europ J Integr Medic. 2020;35:101099.

20. Stephani V, Opoku D, Beran D. Self-management of diabetes in Sub-Saharan Africa: a systematic review. BMC public health. 2018;18(1):1-11.

21. Lee EH, van der Bijl J, Shortridge-Baggett LM, Han SJ, Moon SH. Psychometric properties of the diabetes management self-efficacy scale in Korean patients with type 2 diabetes. Int J Endocrinol. 2015;2015.

22. Becker J, Emmert-Fees KM, Greiner GG, Rathmann W, Thorand B, Peters A, Karl FM, Laxy M, Schwettmann L. Associations between self-management behavior and sociodemographic and disease-related characteristics in elderly people with type 2 diabetes-New results from the population-based KORA studies in Germany. Primary care diabetes. 2020;14(5):508-14.

23. Cichosz SL, Jensen MH, Hejlesen O. Cognitive impairment in elderly people with prediabetes or diabetes: A cross-sectional study of the NHANES population. Primary care diabetes. 2020;14(5):455-9.

24. Werfalli MM, Kalula SZ, Manning K, Levitt NS. Does social support effect knowledge and diabetes self-management practices in older persons with Type 2 diabetes attending primary care clinics in Cape Town, South Africa?. PloS one. 2020;15(3):e0230173.

25. Berhe KK, Gebru HB, Kahsay HB, Kahsay AA. Assessment of self care management and its associated factors among type 2 diabetes patients in Mekelle Hospital and Ayder Referral Hospitals, Mekelle City, Tigray, Northern Ethiopia, 2012/13. Glob J Med Res. 2017;17(1):2249-4618.

26. Xu Y, Pan W, Liu H. Self-management practices of Chinese Americans with type 2 diabetes. Nurs Health Sci. 2010;12(2):228-34.

27. Dashtian M, Eftekhar Ardebili H, Karimzadeh Shirazi K, Shahmoradi M, Azam K. Predicting factors affecting medication adherence and physical activity in patients with type-2 diabetes mellitus based on the theory of planned behavior. Journal of School of Public Health and Institute of Public Health Research. 2017;15(2):133-46. [Persian]

28. Gholamaliei B, Karimi-Shahanjarini A, Roshanaei G, Rezapour-Shahkolaei F. Medication adherence and its related factors in patients with type II diabetes. J Educ Community Health. 2016 Mar 10;2(4):3-12. [Persian]

29. Kong LN, He S, Li L, Lei QS, Wang T, Yao Y. Factors for self-management activities among rural patients with chronic hepatitis B: A cross-sectional study. J Clin Nurs. 2019;28(21-22):3949-56.

30. Naderiravesh N, Bahadoram S, Shiri H, Zohari AS, Khodakarim S, Hasanian LF. Examining the correlation of adherence to warfarin therapy with demographic characteristic. Iranian Journal of Critical Care Nursing (IJCCN). 2015;8(2):103-8. [Persian] 
31. Sajjadi M, Mohammadpour A, Mahmoudi M. Correlation between Uncertainty in the Illness, Demographic and Clinical Factors with Adherence to Treatment in Patients with Cancer. Journal Of Sabzevar University Of Medical Sciences. 2017;24(3):205-10. [Persian]

32. Tol A, Shojaezadeh D, Eslami A, Alhani F, Mohajeri TM, Sharifirad GR. Analyses of Some Relevant Predictors on Self-Management of Type 2 Diabetic Patients. Hospital. 2011;10(3):38. [Persian]

33. Lewis CP, Newell JN. Patients' perspectives of care for type 2 diabetes in Bangladesh-a qualitative study. BMC public health. 2014;14(1):1-7.

34. Arabshahi A, Gharlipour Z, Alipour SA, Mohebi S. Assessment of Adherence to Self-Care Behaviors in Hypertensive Patients in Qom City (Iran). Qom Univ Med Sci J. 2020;14(2):55-66. [Persian]

35. Tanharo D, Ghods R, Pourrahimi M, Abdi M, Aghaei S, Vali N. Adherence to Treatment in Diabetic Patients and Its Affecting Factors. Pajouhan Scientific Journal. 2018;17(1):37-44. [Persian]

36. Banaei A, Hashemi B, Bakhshandeh M, Mofid B. Trade-off between the conflicting planning goals in correlation with patient's anatomical parameters for intensity-modulated radiotherapy of prostate cancer patients. J Radiother Pract. 2019;18(3):232-8.

37. Hashemi MS, Akbari A, Parvizi A. New Physically Consistent Yield Model to Optimize Material Design for Functionally Graded Vessels. Journal of Failure Analysis and Prevention. 2020 18:113. [Persian]

38. Hashemi MS, Baniassadi M, Baghani M, George D, Remond Y, Sheidaei A. A novel machine learning based computational framework for homogenization of heterogeneous soft materials: application to liver tissue. Biomechan Model Mechanobiol. 2019 10:1-2.

39. Bastani F, Hashemi S, Bastani N, Haghani H. Impact of preconception health education on health locus of control and self-efficacy in women. EMHJ-Eastern Mediterranean Health Journal, 16 (4), 396-401, 2010. 